\title{
Correction to: The pentose phosphate pathway in industrially relevant fungi: crucial insights for bioprocessing
}

\author{
Audrey Masi ${ }^{1,2}\left(\mathrm{D} \cdot\right.$ Robert L. Mach ${ }^{2}\left(\mathrm{D} \cdot\right.$ Astrid R. Mach-Aigner ${ }^{1,2}$ (D) \\ Published online: 27 October 2021 \\ C Springer-Verlag GmbH Germany, part of Springer Nature 2021
}

Correction to: Applied Microbiology and Biotechnology (2021) 105:4017-4031 https://doi.org/10.1007/s00253-021-11314-x

The Fig. 1 of the published version contained a mistake. The correct image is shown below.

The original article can be found online at https://doi.org/10.1007/ s00253-021-11314-x.

Astrid R. Mach-Aigner

astrid.mach-aigner@tuwien.ac.at

1 Christian Doppler Laboratory for Optimized Expression of Carbohydrate-Active Enzymes, Institute of Chemical, Environmental and Bioscience Engineering, TU Wien, Gumpendorfer Str. 1a, A-1060 Vienna, Austria

2 Institute of Chemical, Environmental and Bioscience Engineering, TU Wien, Gumpendorfer Str. 1a, A-1060 Vienna, Austria 


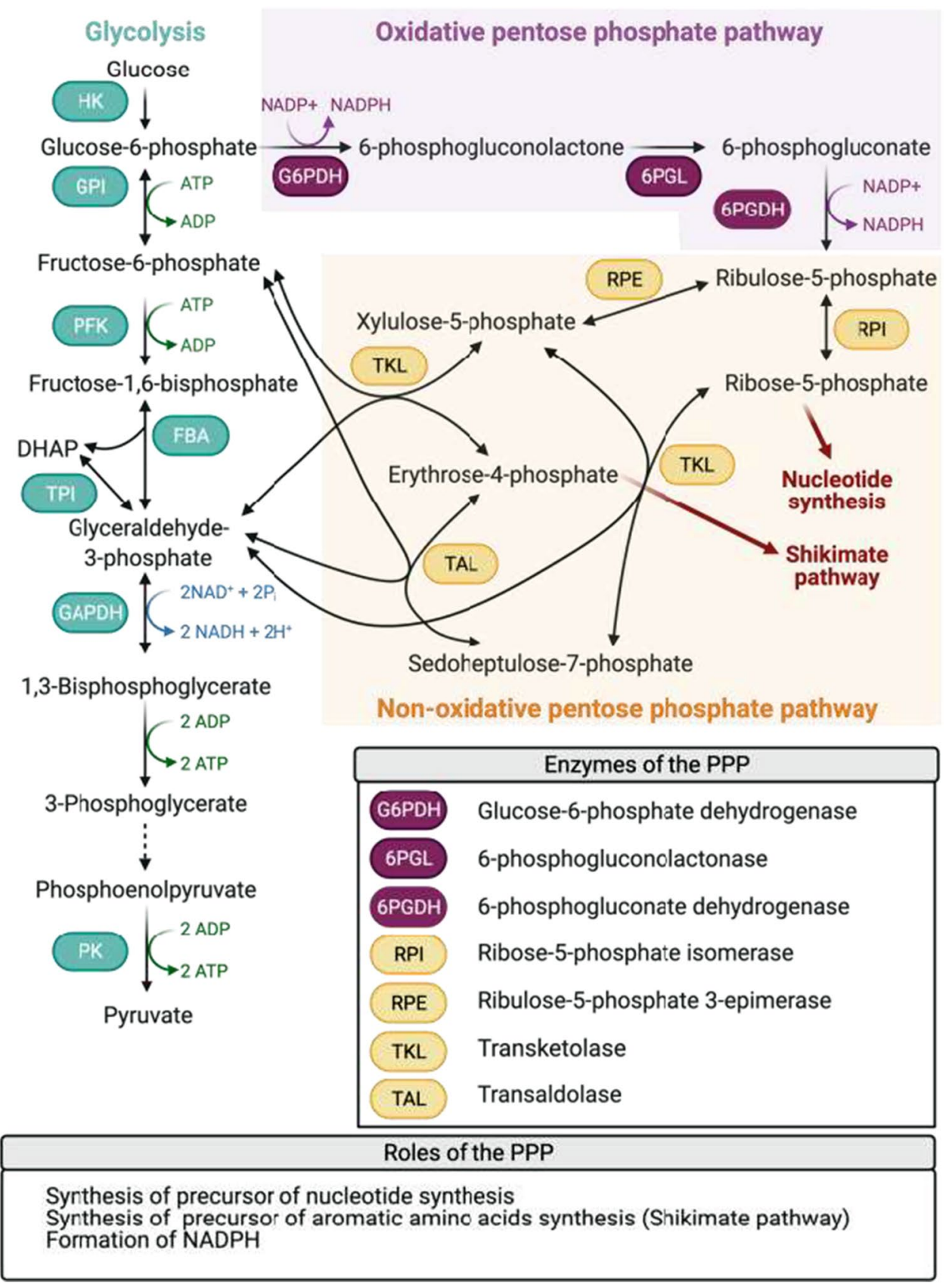

Publisher's note Springer Nature remains neutral with regard to jurisdictional claims in published maps and institutional affiliations. 